\title{
Gute Noten für die Hausärzte
}

\author{
Chefredakteur Dr. med. Dirk Einecke
}

\section{EINNAHME VON MEDIKAMENTEN}

\section{Besser nicht mit Obstsaft}

Dass Grapefruitsaft die Wirkspiegel zahlreicher Medikamente (z. T. dramatisch) erhöhen kann, ist seit vielen Jahren bekannt. Verantwortlich dafür ist eine Blockade des abbauenden Enzyms $\mathrm{CY}_{3} \mathrm{~A}_{4}$. Jetzt haben Forscher entdeckt, dass bei bestimmten Medikamenten auch der umgekehrte Effekt eintreten kann. Diese Medikamente benötigen für die Passage aus dem Dünndarm ins Blut ein Transportprotein und dieses Protein wird von dem Grapefruit-Inhaltsstoff Naringin gehemmt. Beeinträchtigt wird z. B. die Resorption des Antihistaminikums Fexofenadin, des Betablockers Atenolol, des Immunsuppressivums Cyclosporin und einiger Antibiotika (z. B. Ciprofloxacin, Levofloxacin). Da Orangen- und Apfelsaft naringinähnliche Substanzen enthalten,

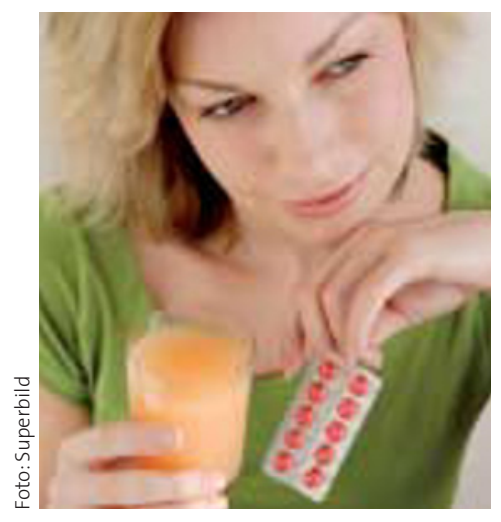

Hier besteht die Gefahr von Fehldosierungen!

können sie die Wirkung der genannten Medikamente ebenfalls abschwächen. In der Regel sollten Medikamente daher nur mit Wasser eingenommen werden.

Tagung der American Chemical Society, Philadelphia/PA, 20. August 2008

\section{KBV-UMFRAGE}

\section{Wie Patienten die medizinische Versorgung durch den Hausarzt bewerten}

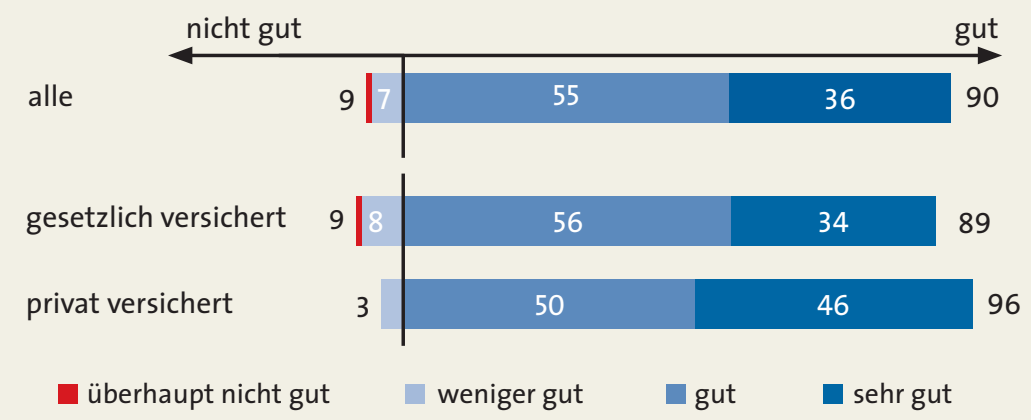

Neun von zehn Deutschen geben ihrem Hausarzt die Note „gut“ oder „sehr gut“. Die Zufriedenheit ist nicht abhängig von der Schwere der Erkrankung. Auch bei Patienten mit schlechtem Allgemeinzustand ist das Vertrauen in den Hausarzt ungebrochen. Zwischen gesetzlich Versicherten und Privatpatienten gibt es nur marginale Unterschiede (siehe Grafik).
Herausgefunden hat diese Zahlen die Forschungsgruppe Wahlen, die im Auftrag der KBV 4315 Bundesbürger telefonisch befragte. $82 \%$ der Befragten hatten innerhalb der letzten zwölf Monate einen Arzt besucht. $42 \%$ suchten ausschließlich ihren Hausarzt auf, $17 \%$ ausschließlich einen Facharzt und $41 \%$ waren sowohl beim Haus- als auch beim Facharzt.

\section{WAS DER LEBENSSTIL AUSMACHT}

\section{Schlaganfallrisiko lässt sich halbieren}

Ein gesunder Lebensstil bietet nicht nur Schutz vor chronischen Erkrankungen wie Diabetes und KHK. Die präventive Wirkung erstreckt sich auch auf das Schlaganfallrisiko, wie die Auswertung entsprechender Daten von mehr als 110000 Personen belegt.

Von den registrierten ischämisch bedingten Schlaganfällen (1559 bei den Frauen, 994 bei den Männern) ließen sich über $50 \%$ auf einen ungesunden Lebensstil zurückführen. Der Anteil der lebensstilbedingten hämorrhagischen Schlaganfälle war etwas geringer. Ein gesunder Lebensstil war definiert durch Rauchverzicht, einen BMI unter $25 \mathrm{~kg} / \mathrm{m}^{2}$, moderate körperliche Aktivität für mindestens 30 Minuten pro Tag, mäßigen Alkoholkonsum und eine ausgewogene Ernährung.

Circulation 2008;

DOI:10.1161/CIRCULATIONAHA.108.781062

\section{IMMUNOLOGIE}

\section{Stress verschlimmert Allergien}

Stress und Anspannung können dazu führen, dass allergische Reaktionen stärker ausfallen und länger anhalten. Das ergab eine Laborstudie mit 28 Allergikern, die entweder entspannen durften oder einer psychisch belastenden Situation ausgesetzt wurden. Mäßige Anspannung führte dazu, dass die Ouaddeln im PrickTest etwa um $75 \%$ größer ausfielen. Bei starker Anspannung waren die Quaddeln sogar doppelt so groß wie ohne Stress. Hier kam es am Folgetag außerdem viermal so oft zu verstärkten allergischen Reaktionen. Die Studienautoren vermuten, dass die unter Stress erhöhten Serumspiegel von Katecholaminen und Interleukin- 6 für die Ausweitung der allergischen Reaktion mit verantwortlich sind. Tagung der American Psychological Association, Boston, 14. August 2008 